\title{
Age and race differences in racial stereotype awareness and endorsement
}

\author{
Kristine E. Copping ${ }^{1}$, Beth Kurtz-Costes ${ }^{1}$, Stephanie J. Rowley ${ }^{2}$, Dana Wood ${ }^{3}$ \\ 'Department of Psychology, University of North Carolina \\ ${ }^{2}$ Department of Psychology, University of Michigan \\ ${ }^{3}$ Department of Education, University of California
}

\author{
Correspondence concerning this article should \\ be addressed to Kristine E. Copping, \\ Department of Psychology, Huntingdon \\ College, 1500 East Fairview Avenue, \\ Montgomery, AL 36106, USA. \\ E-mail: kcopping@huntingdon.edu
}

Kristine Copping is now at the Department of Psychology, Huntingdon College.

Data collection for this study was supported by National Institute of Mental Health grant P50 MH52429 to Robert Cairns. Authors were supported during the writing of this report by NSF grant DRL-0819079.

\begin{abstract}
Age and race differences in race stereotype awareness and endorsement were examined in 382 Black and White fourth, sixth, and eighth graders. Youths reported their own beliefs and their perceptions of adults' beliefs about racial differences in ability in two domains: academics and sports. Children's own endorsement of race stereotypes was highly correlated with their perceptions of adults' race stereotypes. Blacks reported stronger traditional sports stereotypes than Whites, and 4th- and 6th-grade Blacks reported roughly egalitarian academic stereotypes. At every grade level, Whites reported academic stereotypes that favored Whites, and 6th- and 8thgrade Whites reported sports stereotypes that favored Blacks. Results support the tenets of status theory and have implications for identity development and achievement motivation in adolescents.
\end{abstract}

doi: 10.1111/jasp.12061

Stereotypes about race differences in cognitive and noncognitive abilities continue to be prevalent in the United States (Bobo, 2001; Kellow \& Jones, 2008). American youths are frequently exposed to negative images of African Americans in the media, and when a successful Black person is portrayed, he or she is often an athlete or some type of entertainer (Hudley \& Graham, 2002; Ward, 2004). A robust literature in recent decades has shown that racial stereotypes about differences in skills influence the performance of adults (Schmader, Jones, \& Forbes, 2008; Sekaquaptewa, Waldman, \& Thompson, 2007). However, less research has examined the development of awareness of domainspecific race stereotypes and children's own race stereotype endorsement.

Understanding age and race differences in stereotype awareness and endorsement is important because of the role these beliefs may play in children's development. Research suggests that African-American children who are aware of negative stereotypes about their group's academic abilities are more susceptible to stereotype threat processes and more likely to perceive negative interactions with Whites as discriminatory than children who do not yet know about these stereotypes (McKown \& Strambler, 2009). Stereotype threat processes and experiences with racial discrimination, in turn, may impede youths' academic performance (Good, Aronson, \& Inzlicht, 2003; Wong, Eccles, \& Sameroff, 2003) and contribute to lower levels of general psychological wellbeing (Bryant, 2007; Cooper, McLoyd, Wood, \& Hardaway, 2008). Children's own endorsement of race stereotypes is likely to be related to self-perceptions and behaviors in the stereotyped domain. For example, prior research shows that African-American youths who endorse traditional academic race stereotypes hold lower perceptions of their own academic abilities than youths who do not hold such beliefs (Evans, Copping, Rowley, \& Kurtz-Costes, 2011; Okeke, Howard, Kurtz-Costes, \& Rowley, 2009).

\section{Race stereotype development}

Stereotypes are shared knowledge structures pertaining to specific social groups (Devine, 1989). In the United States, common stereotypes are that African Americans are less intellectually capable than Whites and are more naturally talented in sports (Eastman \& Billings, 2001; Kellow \& Jones, 2008). Little research has addressed the development of children's awareness and endorsement of these stereotypes. In an investigation of children aged 6-10, McKown and Weinstein (2003) found that older children were more aware of 
race-based stereotypes about academic ability than younger participants. Rowley, Kurtz-Costes, Mistry, and Feagans (2007) found that early adolescents (sixth and eighth graders) were more likely than younger children to endorse traditional race stereotypes about academics. All age groups in their study reported that Blacks are more athletically talented than Whites.

According to experiential theory, children's developing understanding of the world emerges as a result of the interaction between the cognitive resources available to the child and the child's experiences of the world (Nelson, Plesa, \& Henseler, 1998). As Nelson and her colleagues argue (Nelson, 1996; Nelson et al., 1998), this perspective posits that children's knowledge is co-constructed based on interactions with social partners and therefore is profoundly shaped by the child's social/cultural environment. Thus, an increase in knowledge of race stereotypes would be expected developmentally both because of greater sophistication in cognitive skills and also because of age-associated increases in general knowledge/beliefs held by influential social others in the child's community (Kurtz-Costes, Rowley, Harris-Britt, \& Woods, 2008). Increased knowledge about and endorsement of stereotypes might be anticipated in early adolescence in particular because of increased salience of academic performance in middle schools (e.g., due to academic tracking) and because of race differences in assignment to ability groups (Eccles \& Midgley, 1989; Losen \& Orfield, 2002; Rowley, Kurtz-Costes, \& Cooper, 2010). In addition to these contextual changes across the transition to middle school, important cognitive changes occur as youths move into adolescence, including increased perspective taking, abstract thinking, and awareness of race (Quintana, 1998). Race stereotype awareness and endorsement are examined in the current study with a sample of fourth, sixth, and eighth graders. We hypothesized that during this age span, cognitive changes would combine with new life experiences to result in older children reporting traditional beliefs for both stereotype awareness and endorsement.

Influential adults such as parents and teachers are an important source of information for children. Children are likely to draw from their perceptions of adults' beliefs (i.e., their stereotype awareness) to form their own beliefs about the social groups to which they and others belong. Research in gender stereotypes suggests that teachers and parents' gender-related beliefs about academic performance influence children's views of their own academic abilities (Jacobs, 1991; Tiedemann, 2001). Jacobs (1991) found that even though girls in their sample outperformed boys in math, girls had lower self-perceptions of math ability than boys, and children's self-perceptions were related to the strength of their parents' stereotypes. Unlike Jacobs, in the current study, we did not obtain adults' self-reported stereotype endorsement; rather we asked for the children's perceptions of adults' stereotypes. We asked children to report their perceptions of adults' beliefs in order to capture the child's interpretation of adults' behaviors, actions, and opinions related to race, and to determine the relation between youths' perceptions of adults' stereotypes and youths' own stereotypes. We focused on the beliefs of adults in general rather than asking children specifically about teachers or parents because we were interested in children's knowledge/beliefs about their social/cultural world rather than the beliefs of specific individuals (e.g., parents), which might differ from the broader cultural perspective.

\section{Social status theory and race stereotypes}

In addition to group differences linked to age, stereotype endorsement may be affected by social group status. According to Tajfel's (1970) social identity theory, people naturally display a positive bias for members of their own social groups. In-group bias is believed to occur because of selfenhancement-that is, positive views of one's social group are a positive reflection on the self. In-group bias has been shown in children and adults using experimental methods with random assignment to artificially created groups (Bigler, Jones, \& Lobliner, 1997) as well as more naturalistic research (Maccoby, 1998; Otten, 2004). For example, Bigler et al. (1997) randomly assigned 6-9-year-olds to one of two color groups in three different classroom conditions. When teachers made functional use of the color groups (i.e., color-based seating charts and line formation), students were more likely to favor their in-group over their out-group. Based upon this theory and research, we anticipated that children in our study would all show some degree of in-group bias, reporting that members of their own race are viewed in a more positive light than the other race.

In addition, we expected group differences in reports based on group status. Although ample research has documented the phenomenon of in-group bias, classic social psychology research shows that members of high-status groups are more likely than members of low-status groups to display in-group preference. Such status differences have been found when group status was artificially manipulated through experimental assignment to groups (Bigler, Brown, \& Markell, 2001; Nesdale \& Flesser, 2001). In an extension of status theory based on these ideas, Rowley et al. (2007) argued that stereotype endorsement may be influenced by the relative status of one's social group. Whereas prior research and theory on status differences used experimental manipulation whereby status was confounded with valence, in the real world of gender and race in the United States, both positive and negative stereotypes are linked to each racial and gender group. For example, although Blacks are traditionally viewed 
as less capable academically than Whites, Blacks are viewed as more capable in sports and music skills.

Rowley et al. (2007) argued that girls and African Americans, who are low status according to historical cultural norms in the United States, might be less likely to report stereotypes that reflected negatively on themselves (i.e., as girls and African Americans, respectively) than would members of high-status groups (i.e., boys and Whites, respectively), because members of high-status groups, by virtue of their status, have less need to self-enhance. By the same token, members of low-status groups might be more likely to endorse stereotypes that reflect positively on their social group - again, because of group differences in desire/need to self-enhance. The results of Rowley et al. were consistent with those hypotheses: Low-status group members (girls and Blacks) endorsed favorable stereotypes about their social group, but were less likely than high-status group members (boys and Whites) to endorse negative stereotypes about their social group (see also Nesdale \& Flesser, 2001).

\section{The present study}

Using a cross-sectional sample of 382 African-American and White fourth, sixth, and eighth graders, we examined age and race differences in race stereotype endorsement and awareness. Children were asked to report their own race stereotypes and their perceptions of adults' race stereotypes (i.e., stereotype awareness) concerning Black and White children's academic and sports abilities. Because children are likely to internalize the beliefs of adult-socializing agents as argued in experiential theory, our first hypothesis was that for all age and race groups, children's perceptions of adults' stereotypes would be related to their own stereotype endorsement. We also expected that stereotype endorsement and awareness would vary as a function of children's age and racial group membership; hypotheses concerning these age and race differences were guided by a synthesis of social identity theory, status theory, and experiential theory.

According to experiential theory (Kurtz-Costes et al., 2008; Nelson et al., 1998), older children have more advanced cognitive skills and have encountered more world knowledge than younger children; therefore, they are more likely to have developed beliefs that are held within their social/cultural world. Thus, our second hypothesis was that compared to younger children, on average, older children would report stronger endorsement and awareness of traditional stereotypes (i.e., that Whites are more competent than Blacks in academic domains, and that Blacks are more competent than Whites in sports).

Our third hypothesis reflected the impact of in-group bias. On the one hand, we expected that younger children of both racial groups would report that their racial group excelled both academically and athletically compared to the other group. That is, in both domains, White fourth graders would report White advantage and Black fourth graders would report Black advantage. Older youths, in contrast, were expected to report stereotypes that reflected both in-group bias and their growing awareness of traditional stereotypes. Therefore, we expected that sixth and eighth graders would report awareness and endorsement of traditional stereotypes, but that each group would favor their own group in terms of the magnitude of group differences. Thus, for instance, although both groups might report on average that Blacks are better than Whites athletically, the means of Black sixth and eighth graders would be larger than the means of White sixth and eighth graders.

In addition to anticipating these age differences predicted by a synthesis of experiential theory and in-group bias, we expected group status differences in reports link to the respondent's race and the stereotype domain (academics vs. sports). According to Rowley et al.'s (2007) reasoning, African-American youths who are aware of their group's relatively low status may enhance positive stereotypes about their group and minimize negative stereotypes as a selfprotective strategy. Therefore, we expected that Black youths' sports stereotypes - which reflect positively on their racial group-would be stronger than White youths' academic stereotypes - which reflect positively on Whites. In contrast, Black youths' reports of academic stereotypes were expected to be weaker than White youths' sports stereotypes (i.e., White youths would be more likely than Black youths to report stereotypes that reflect negatively on their racial group). If age differences emerged in these group differences, we expected that older youths would be more likely to show status effects than younger youths. By virtue of their additional experience and exposure to cultural knowledge in comparison to younger children, Black adolescents would be aware both of traditional stereotypes and of the relative lower status of Blacks in U.S. society. Accordingly, we hypothesized that the sports stereotypes of Black eighth graders would show the strongest in-group bias of all stereotypes examined in this study.

To summarize, our hypotheses were as follows: (1) Consistent with experiential theory, children's own stereotype endorsement would be related to their perceptions of adults' stereotypes within each domain. (2) Also as posited by experiential theory, older children would report more traditional stereotypes than younger children both for their own beliefs and their perceptions of adults' beliefs. (3) We expected in-group bias to be evident in reports of all youths. Younger youths were expected to favor their own race for both academics and sports. Whereas we expected that older youths would be more likely than younger youths to report traditional stereotypes within each domain, we expected that their reports would favor their own racial group in terms of the magnitude of each stereotype (i.e., Whites would report 
greater White advantage in academics than Blacks; Blacks would report greater Black athletic advantage than Whites). (4) Finally, consistent with status theory, Black youths' reports of academic stereotypes were expected to be weaker than the sports stereotypes of White youths, and Black youths' sports stereotypes were expected to be stronger than the academic stereotypes reported by Whites. Moreover, the sports stereotypes of older Black children were expected to be stronger than the stereotypes of all other groups.

\section{Method}

\section{Participants}

Data for this report were drawn from the Children's Beliefs about Stereotypes project, a research study that included 687 4th-, 6th-, and 8th-grade students who completed surveys during the 1999-2000, 2000-2001, and 2001-2002 school years. Because one goal of the project was to develop a reliable and valid measure of stereotypes, not all youths completed all measures. In the current paper, we report data from the 382 youths who completed the measures reported here. The other 305 participants did not complete a direct comparison measure of stereotype endorsement. Of the 382 youths who contributed data for the current study, 217 of them also contributed data that were summarized in Rowley et al. (2007). Although age and race differences in academic and sports stereotype endorsement were examined by Rowley and her colleagues, none of the current measures overlap with that paper. In other words, 217 of the 448 participants in Rowley et al. completed both direct comparison stereotype measures (reported in this paper) and indirect comparison measures (reported in Rowley et al., 2007).

Participants were 382 (160 boys, 222 girls) fourth (117 Whites, 44 Blacks), sixth (66 Whites, 45 Blacks), and eighth graders (68 Whites, 42 Blacks) living in the southeastern region of the United States. Mean ages were 9.5 years $(S D=.53)$ for fourth graders, 11.5 years $(S D=.64)$ for sixth graders, and 13.5 years $(S D=.57)$ for eighth graders. Nearly all participants resided in counties where the population was approximately 15\% African American and most other residents were White. About 1\% of participants resided in a county where the population was approximately $40 \%$ African American and most other residents were White. In addition, almost $100 \%$ of participants attended schools where $35 \%$ or less of the student body was African American and most other students were White.

\section{Measures and procedure}

Children's beliefs about the abilities of Whites and Blacks in academics (e.g., reading, math, science, grades, smartness) and sports were assessed with 5-point Likert scale items. For example, the item "I think that in sports" was followed by a scale with $1=$ "Whites are much better than Blacks," 2 = "Whites are a little better than Blacks," 3 = "Whites and Blacks are the same," $4=$ Blacks are a little better than Whites," and $5=$ "Blacks are much better than Whites." One item assessed beliefs about sports, and five items assessed beliefs about academics.

Children also rated their perceptions of adults' stereotypes with a parallel set of items. For example, for the item about sports, the prompt read, "Most grownups think that in sports," followed by the same response scale. Academic items were averaged to create a single score $(\alpha=.81$ for children's own beliefs and .84 for their perceptions of adults' beliefs), which was then subtracted from 6 to yield a possible range of 1-5 where higher scores reflected more traditional stereotypes. The sports item also had a possible range of $1-5$, with higher scores indicating more traditional beliefs. Additional measures were administered which are not included in this report.

Written parental-informed consent was required for study participation. Children were administered self-report questionnaires by African-American and European American research assistants in small groups at their schools. At the end of the single session each participant selected a small gift (e.g., stress ball, key chain, flashlight).

\section{Results}

Prior to running the analyses, data were screened for multivariate outliers using Cook's distance $(D)$ procedures. Cook's $D$ statistics were calculated separately for each race/grade group. As recommended by Stevens (1984), two cases (one African-American sixth grader and one White eighth grader) with Cook's $D$ values greater than 1 were removed from the dataset. Means and standard deviations for the children's race stereotypes and their perceptions of adults' race stereotypes about academics and sports are presented in Table 1 for each grade level and race group. Higher scores represent traditional beliefs (i.e., Blacks are better than Whites in sports; Whites are better than Blacks in academics); scores close to 3 indicate egalitarian reports; and low scores represent nontraditional beliefs.

\section{Students' perceptions of adult stereotypes and their own stereotype endorsement}

Pearson's product correlations were used to assess the relation between children's perceptions of adult stereotypes and their own stereotype endorsement. Correlations between all pairs of study variables appear in Table 2 . As predicted in the first hypothesis, children who endorsed more traditional race stereotypes also reported that they think adults hold more 
Table 1 Means and Standard Deviations of Youths' Stereotype Endorsement and Perceptions of Adults' Stereotypes, by Grade and Race

\begin{tabular}{|c|c|c|c|c|c|c|}
\hline & \multicolumn{2}{|c|}{ Fourth graders } & \multicolumn{2}{|c|}{ Sixth graders } & \multicolumn{2}{|l|}{ Eighth graders } \\
\hline & $\begin{array}{l}\text { Whites } \\
M(S D)\end{array}$ & $\begin{array}{l}\text { Blacks } \\
M(S D)\end{array}$ & $\begin{array}{l}\text { Whites } \\
M(S D)\end{array}$ & $\begin{array}{l}\text { Blacks } \\
M(S D)\end{array}$ & $\begin{array}{l}\text { Whites } \\
M(S D)\end{array}$ & $\begin{array}{l}\text { Blacks } \\
M(S D)\end{array}$ \\
\hline \multicolumn{7}{|c|}{ Stereotype endorsement } \\
\hline Academic & $3.23(.44)$ & $3.00(.48)$ & $3.14(.43)$ & $3.03(.39)$ & $3.17(.35)$ & $3.07(.32)$ \\
\hline Sports & $3.02(.57)$ & $3.45(.82)$ & $3.31(.68)$ & $3.71(.84)$ & $3.39(.60)$ & $3.64(.85)$ \\
\hline \multicolumn{7}{|c|}{ Perceptions of adults' stereotypes } \\
\hline Academic & $3.33(.48)$ & $2.92(.52)$ & $3.22(.43)$ & $3.14(.54)$ & $3.35(.47)$ & $3.33(.54)$ \\
\hline Sports & $2.97(.72)$ & $3.50(.90)$ & $3.25(.72)$ & $3.67(.83)$ & $3.43(.61)$ & $3.62(1.01)$ \\
\hline & $n=117$ & $n=44$ & $n=66$ & $n=45$ & $n=68$ & $n=42$ \\
\hline
\end{tabular}

Note. Higher scores reflect more traditional stereotypes.

Table 2 Bivariate Correlations between Variables

\begin{tabular}{lllll}
\hline Variable & 1 & 2 & 3 & 4 \\
\hline 1. Child's own academic stereotypes & - & & & \\
2. Child's own sports stereotypes & $-.15^{*}$ & - & & \\
$\begin{array}{l}\text { 3. Perception of adults' academic } \\
\quad \text { stereotypes }\end{array}$ & $.63^{* *}$ & -.03 & - & \\
$\begin{array}{l}\text { 4. Perception of adults' sports } \\
\quad \text { stereotypes }\end{array}$ & -.05 & $.61^{* *}$ & -.05 & - \\
\hline
\end{tabular}

Note. ${ }^{*} p<.01 .{ }^{* *} p<.001$.

traditional race stereotypes for both academics and sports, $r(380)=.63$ and .61 , respectively, $p s<.001$. Correlations between academic and sports race stereotypes were less than 0.16 .

A $3($ Grade $) \times 2($ Race $) \times 2($ Domain $) \times 2($ Belief Source $)$ repeated-measures analysis of variance (ANOVA) was used to analyze group differences in children's reports of their own and their perceptions of adults' race stereotypes. Grade and race were between-subject factors, and domain (academic and sports abilities) and belief source (the child's stereotypes vs. the child's perception of adults' stereotypes) were withinsubject factors. Mean comparisons were based on 95\% confidence intervals. ${ }^{1}$

\footnotetext{
${ }^{1}$ We did not have adequate statistical power to reliably test race by gender interactions in children's reports. Nonetheless, in exploratory analyses we examined gender differences in reports. The main effect of gender was significant, $F(1,370)=8.70, p=.003$. Across grades, race, domain, and source, boys reported more traditional stereotypes than girls, $M_{\mathrm{B}}=3.37, S D=.44$; $M_{\mathrm{G}}=3.24, S D=.34, d=.31$. All two-way interactions involving gender were nonsignificant. The Gender $\times$ Domain $\times$ Source interaction was significant, $F(1,370)=4.86, p=.028$. Girls reported that adults hold stronger academic stereotypes than girls' own views, whereas girls' reports of sports stereotypes did not differ for awareness versus endorsement. The reverse was found among boys: Boys reported awareness and endorsement of academic stereotypes of equal magnitude, but reported that adults hold stronger sports stereotypes than the views of the boys themselves.
}

\section{Age differences in traditionality and in-group bias}

According to Hypothesis 2, older children would report more traditional stereotypes than younger children. Thus, the main effect of grade would be significant. Hypothesis 2 was supported: The main effect of grade was significant, $F(2$, $376)=8.21, p<.001$. Across domains, belief source, and race, fourth graders $\left(M_{4 \text { th }}=3.18, S D=.34\right)$, were less traditional than sixth and eighth graders $\left(M_{6 \text { th }}=3.31, S D=.40\right.$; $\left.M_{8 \text { th }}=3.38, S D=.41\right), d=.45$.

We also expected that this main effect would be qualified by a Grade $\times$ Race $\times$ Domain interaction. Namely, according to Hypothesis 3, although youths were expected to show increases in traditionality with age, in-group bias was expected at each grade level and particularly among younger children. Thus, although stereotype reports were expected to be more traditional among older youths than younger youths, we expected that the three-way interaction would show that Whites would report a stronger White advantage for academics and Blacks would report a stronger Black advantage for sports than the other racial group. As expected, the Grade $\times$ Race $\times$ Domain interaction was significant, $F(2$, 376 ) $=3.40, p=.035$ (see Figure 1 ). Averaging across children's own beliefs and their perceptions of adults' beliefs, 6th- and 8th-grade Blacks reported higher traditional academic stereotypes than 4th-grade Blacks $\left(M_{4 \mathrm{~B}}=2.96\right.$, $\left.S D=0.43 ; M_{6 \mathrm{~B}}=3.08, S D=0.43 ; M_{8 \mathrm{~B}}=3.20, S D=0.35\right)$, $d=.43$. Mean scores of White students at all three ages indicated a belief that Whites are more academically talented than Blacks, and 4th- and 6th-grade Whites reported stronger academic stereotypes than Black fourth and sixth graders $\left(M_{4 \mathrm{~W}}=3.28, S D=0.41 ; M_{6 \mathrm{~W}}=3.18, S D=0.41 ; M_{8 \mathrm{~W}}=3.26\right.$, $S D=0.38), d=.76$ and .24 , respectively. The mean scores of 8th-grade Black children and 8th-grade White children did not differ.

Supporting predictions based on experiential theory, older 6th- and 8th-grade Whites reported stronger traditional 


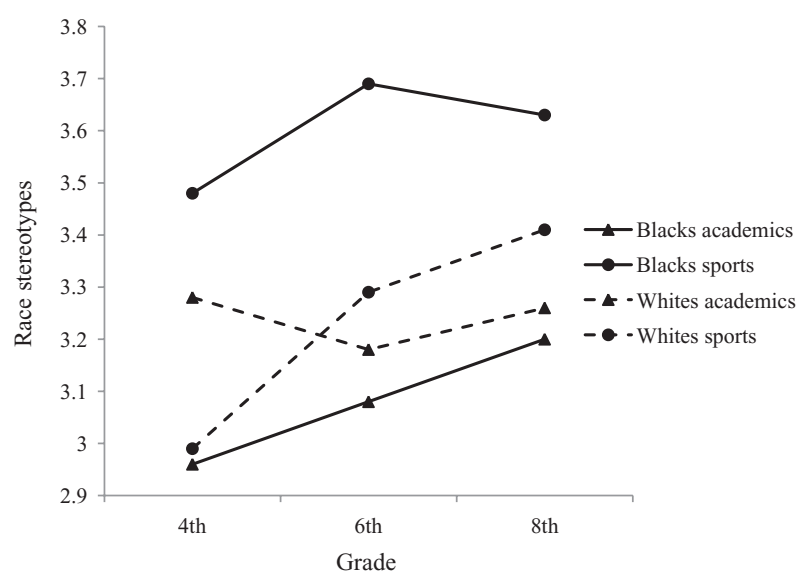

Figure 1 Mean scores for Black and White fourth, sixth, and eighth graders' reports of racial stereotypes about academic and sports abilities. Scores are averaged across perceptions of adults' stereotypes and child's own stereotype endorsement.

sports stereotypes than 4th-grade Whites $\left(M_{4 \mathrm{~W}}=2.99\right.$, $\left.S D=0.52 ; M_{6 \mathrm{~W}}=3.29, S D=0.63 ; M_{8 \mathrm{~W}}=3.41, S D=0.57\right)$, $d=.64$. Black children reported strong traditional beliefs about race differences in sports ability at all three ages $\left(M_{4 \mathrm{~B}}=3.48, S D=0.78 ; M_{6 \mathrm{~B}}=3.69, S D=0.80 ; M_{8 \mathrm{~B}}=3.63\right.$, $S D=0.79)$. Black children were expected to report stronger sports stereotypes than White youths. As anticipated and consistent with the idea of in-group bias, Black children reported stronger sports stereotypes than White children at each grade level, $d s=.74, .56$, and .32 , respectively.

\section{Group status and stereotype reports}

Status effects were predicted in Hypothesis 4: Black youths were expected to report stronger stereotypes that reflected positively on Blacks and weaker stereotypes that reflected negatively on Blacks in comparison to the reports of White students. Thus, support for this hypothesis would appear either as a Race $\times$ Domain interaction or by a significant Race $\times$ Grade $\times$ Domain interaction. The Race $\times$ Domain interaction was significant, $F(1,376)=38.90, p<.001$. As anticipated in Hypothesis 4, Black youths reported academic stereotypes that were weaker than the sports stereotypes of White youths $\left(M_{\mathrm{BA}}=3.08, S D=0.55 ; M_{\mathrm{WS}}=3.23, S D=0.72\right)$, $d=.23$, and Black youths reported sports stereotypes that were stronger than the academic stereotypes of Whites $\left(M_{\mathrm{BS}}=3.60, S D=0.84 ; M_{\mathrm{WA}}=3.24, S D=0.47\right), d=.53$. In addition, as stated above, this effect was qualified by the significant Race $\times$ Grade $\times$ Domain interaction. That interaction showed that Black youths' reports of sports stereotypes were stronger than the academic stereotypes of Whites at all three grade levels ( $d s=.32, .80$, and .60 for fourth, sixth, and eighth graders, respectively), whereas the academic stereotypes of Blacks were weaker than the sports stereotypes of
Whites among sixth and eighth graders, but not among fourth graders ( $d s=.39$ and .44 for sixth and eighth graders; see Figure 1).

As expected, the sports stereotypes of Black sixth and eighth graders were stronger than the average stereotypes of all other groups. Consistent with Hypothesis 4, the sports stereotypes reported by Black eighth graders were of greater magnitude than the academic stereotypes of White eighth graders, $d=.60$.

The main effect of race was also significant, $F(1$, $376)=6.38, p=.012$, reflecting that across domains, grade, and belief source, Black children reported more traditional race stereotypes than White children. As noted above, this main effect was qualified by the Race $\times$ Grade $\times$ Domain interaction, which showed that the sports stereotypes of Black children drove this effect. The main effect of source and the Source $\times$ Domain interaction were also significant, $F(1$, $376)=4.88$ and 7.44, respectively, $p s=.028$ and .007 . Examination of the interaction showed that, on average, whereas children's perception of adults' academic stereotypes was stronger than their own academic stereotypes $\left(M_{\mathrm{CAcad}}=3.11\right.$, $\left.S D=0.41 ; M_{\text {AAcad }}=3.22, S D=0.50 ; d=.24\right)$, sports scores averaged across race and age groups did not differ in terms of youths' own stereotypes and their perceptions of adults' stereotypes $\left(M_{\text {CSports }}=3.42, S D=0.73 ; M_{\mathrm{ASports}}=3.41, S D=\right.$ $0.81)$. The interactions of Source $\times$ Grade, Source $\times$ Race, Source $\times$ Grade $\times$ Race, Domain $\times$ Source $\times$ Grade, Domain $\times$ Source $\times$ Race, and Domain $\times$ Source $\times$ Grade $\times$ Race were nonsignificant.

In summary, as hypothesized, children's reports of their own stereotypes were strongly correlated with their perceptions of adults' views, and older youths reported more traditional stereotypes than younger youths. Group differences also showed evidence of both in-group bias and status effects. In terms of in-group bias, race differences in sizes of effects were in the direction of in-group bias for all comparisons except eighth graders' reports of academics. As predicted by status theory, Black youths reported stronger stereotypes in the domain in which their racial group is viewed positively and weaker stereotypes in the domain in which their group is viewed negatively than Whites. It should be noted that ANOVAs has low power to detect higher level interactions. Thus, although the higher level interactions involving source were nonsignificant, some of the results reported above may mask differences between youths' reports of their stereotype knowledge (i.e., perceptions of adults' beliefs) and their own stereotype endorsement.

\section{Discussion}

The goal of this study was to assess the academic and sports race stereotypes of Black and White fourth, sixth, and eighth graders, and to test the hypotheses linked to social status 
theory and experiential theory regarding the strength of children's stereotype awareness and endorsement. Our findings provide support for both theories and add to the work of Rowley et al. (2007). In contrast to Rowley et al., we used a stereotype measure that asked children to make direct comparisons of the academic and sports abilities of Blacks and Whites, and in order to address a notable gap in the existing literature, we included measures of children's perceptions of adults' race stereotypes. Our results make three important contributions to the literature on race stereotypes. First, these results contribute to a small but growing body of literature showing that early adolescence is a key developmental period when youths begin to explicitly endorse academic race stereotypes. Second, children's own stereotypes were correlated with their reported perceptions of adults' stereotypes. Third, race differences emerged in reports such that the stereotypes of the strongest magnitude were Black students' reports of race differences in sports abilities. The following sections will address the implications of our results for theoretical understanding of the development of stereotype awareness and endorsement, adolescents' academic motivation and career choices, and suggestions for future research.

\section{Children's awareness and endorsement of stereotypes: experiential and social status theories}

The age and race differences that emerged in stereotype reports were consistent with predictions of both status and experiential theories. In support of experiential theory, as hypothesized, sixth and eighth graders reported more traditional stereotypes on average than fourth graders. These results pinpoint early adolescence as the time when youths' reports shift from in-group bias-reporting that their own social group is better than the out-group - to views that are consistent with beliefs in the wider society. In addition to increased awareness linked to cognitive development, this increase may be related to changes in school structure and climate accompanying the middle school transition such as greater racial diversity in middle school and greater visibility of academic tracking (Graham, 2004; Losen \& Orfield, 2002). The Grade $\times$ Race $\times$ Domain interaction provided further detail and was consistent with predictions of status theory. Although 6th- and 8th-grade White children, members of the high-status group, reported stereotypes that reflected both negatively and positively on their racial group (i.e., traditional sports stereotypes and traditional academic stereotypes), Black youths' reports of academic stereotypes were weaker, and the sports stereotypes of older Black children were of greater magnitude than the academic stereotypes of older White children.

Rowley et al. (2007) used a measure in which children rated social groups separately, and stereotypes were inferred from different ratings of Blacks and Whites. In that study, children reported their own stereotypes, but not their perceptions of adults' beliefs. Overall, the current results are similar to those of Rowley et al. who found that Black fourth graders reported nontraditional beliefs (i.e., Blacks are better than Whites in academics), whereas the average scores of 6th- and 8th-grade Black children showed a modest academic advantage for Whites. Consistent with the current paper, Rowley et al. found that both Black and White youths reported traditional sports stereotypes, with those stereotypes particularly strong among Black youths.

\section{Study implications}

Students' motivational beliefs and values are rooted in their sociocultural environments. For many youths in the United States, the sociocultural environment continues to be shaped by social stratification defined by race and socioeconomic status (Irving \& Hudley, 2005; Williams, Davis, Cribbs, Saunders, \& Williams, 2002). Academic stereotypes influence motivation and achievement through many avenues, including decreased performance due to stereotype threat, altered perceptions of one's own ability, and choices due to differential valuing of domains (Evans et al., 2011; Good et al., 2003; Graham, 2004; Kurtz-Costes et al., 2008). It is important therefore to understand the ages at which youths become aware of racial stereotypes to better formulate interventions that might reduce their deleterious effects for minority youths.

Results of our study show that by early adolescence, Black youths are aware both of stereotypes about race differences in academic abilities, and also of social stereotypes about race differences in athletic abilities. The rich body of literature on stereotype threat has shown that even if an individual does not endorse them, awareness of stereotypes has a detrimental effect on performance by impairing cognitive resources such as reducing working memory capacity (Schmader, Jones, \& Forbes, 2008). These negative performance effects, along with actual stereotype endorsement, might shape the academic choices of Black youths both through push and pull mechanisms. For instance, these stereotypes, including Black youths' strong beliefs about a Black athletic advantage, might lead youths to devalue academic achievement and instead focus their attention on nonacademic pursuits, such as sports, the opposite sex, and appearance (Graham, 2004; Graham, Taylor, \& Hudley, 1998).

One unfortunate way of coping with negative stereotypes is to disengage from or discount the achievement process (C. Steele, 1997). C. M. Steele and Aronson (1995) suggested that members of stigmatized groups who are aware of the negative stereotypes held about their group underperform in situations where their behaviors could serve to confirm negative stereotypes. If group members avoid participating in 
activities (e.g., classroom discussions) in order to avoid confirming a social stereotype, their performance is impeded. Even more striking than the academic stereotypes in the current results are the robust findings regarding youths' race stereotypes about sports abilities. Black youths who view athletic activity as a promising arena for success-fueled also by portrayals in the media of successful Black athletes-may be particularly likely to devalue academic success. The current results - that children are already aware of race academic stereotypes by middle school—are disturbing and likely have implications for the achievement behaviors of both Black and White youths.

A key contribution of this study is the assessment of youths' perceptions of the stereotypes of adults. Our findings indicate that children's own beliefs about disparities between Whites and Blacks' abilities are connected to what they think the adults in their lives believe about differences between racial groups. As predicted, children's reports of their own race stereotypes were highly correlated with their perceptions of adults' race stereotypes for both academics and sports. Children spend much of their time in the company of their parents and teachers. Thus, these influential adults may be instrumental in reducing stereotypical ideation.

On the other hand, youths perceived that adults hold more traditional academic stereotypes than were endorsed by the youths as their own beliefs. Children's perceptions might be accurate: That is, on average, adults may hold more traditional stereotypes than youths. Alternatively, youths may assume that adults hold more traditional stereotypes than they do, or these results could reflect a social desirability effect (i.e., that youths were hesitant to endorse the stereotypes themselves). Notably, even if a Black child does not endorse traditional academic and sports race stereotypes but is aware of others' stereotypes, his or her academic performance and motivation may be guided by this awareness.

\section{Suggestions for future research}

A common limitation of studies of stereotypes is the threat of social desirability effects. In the current study, children may not have reported their honest beliefs about the abilities of Blacks and Whites in sports and academics because they might think it is more socially accepted to have egalitarian views. The forced-choice stereotype measure used may be particularly prone to social desirability because it places Blacks and Whites on opposite sides of the same scale. More indirect assessment methods may result in stronger reports of stereotypes such as the indirect method used by Rowley et al.
(2007) or implicit measures of stereotype activation. In light of this phenomenon, our findings probably underestimate the actual amount of racial disparity that our participants believe exist in the domains of academics and sports. Future research should examine the concordance rates of explicit and implicit measures of stereotypes within the same sample of participants.

The present data were drawn from a cross-sectional sample. To more adequately capture the ways in which children's stereotypes develop over time, longitudinal methods should be employed to document developmental change in stereotype awareness and endorsement. Other important avenues for future research are to examine school, community, and regional factors that shape children's beliefs. For example, schools in which Black and White students are equally represented in honor courses probably lead to different beliefs than school systems in which large race differences are evident in children's assignment to academic tracks.

Future research should also examine the role of gender in these processes. It is possible that boys hold different beliefs than girls, and even more likely that youths' racial stereotypes are gendered in their views of boys versus girls. Using a "first impressions" task, Hudley and Graham (2002) gave middle school youths descriptions of youths and asked them to select which photo went with the description. When given descriptions of high achievers, African-American girls chose photos of Black and White girls (but not boys) with equal frequency, and African-American boys chose Black girls most often. In contrast, when given descriptions of low achievers, all youths were more likely to select boys than girls, and were more likely to select Black or Latino boys than White boys. Although we are not aware of research on the topic, it is likely that stereotypes about race differences in athletic ability are also gender specific in that Black males are viewed as particularly talented athletically. Thus, research is needed examining differential views of boys versus girls as well as their relations to youths' self-views and behavioral choices. Although the strong endorsement of sports stereotypes by Black youths in the current study would be expected to lead to greater involvement in athletics by these youths, it is possible that such beliefs result primarily in racial group pride and have little impact on the academic behavioral choices of most Black youths. Alternatively, these beliefs might have a strong impact on the behavioral choices of a few youths-those who are already engaged in athletic activities-but not on the behaviors of the majority. Future research should attempt to untangle these effects so as to maximize the potential of youths of all races. 


\section{References}

Bigler, R. S., Brown, C. S., \& Markell, M. (2001). When groups are not created equal: Effects of group status on the formation of intergroup attitudes in children. Child Development, 72, 11511162.

Bigler, R. S., Jones, L. C., \& Lobliner, D. B. (1997). Social categorization and the formation of intergroup attitudes in children. Child Development, 68, 530-543.

Bobo, L. (2001). Racial attitudes and relations at the close of the twentieth century. In N. J. Smelser, W. J. Wilson, \& F. Mitchell (Eds.), America becoming: Racial trends and their consequences (pp. 264-301). Washington, DC: National Academic Press.

Bryant, A. (2007). Counseling AfricanAmerican students at a predominately White university: The role of stereotype threat. In S. M. L. Logan, R. W. Denby, \& P. A. Gibson (Eds.), Mental health care in the African American community (pp. 339-357). New York, NY: Haworth Press.

Cooper, S. M., McLoyd, V. C., Wood, D., \& Hardaway, C. (2008). The mental health consequences of racial discrimination for African American adolescents. In S. Quintana \& C. McKown (Eds.), Handbook of race, racism, and the developing child (pp. 278-312). Hoboken, NJ: Wiley \& Sons.

Devine, P. G. (1989). Stereotypes and prejudice: Their automatic and controlled components. Journal of Personality and Social Psychology, 56, 5-18.

Eastman, S. T., \& Billings, A. C. (2001). Voices of sports: Racial and gender stereotyping in college basketball announcing. The Howard Journal of Communications, 12, 183-201.

Eccles, J. S., \& Midgley, C. (1989). Stageenvironment fit: Developmentally appropriate classrooms for young adolescents. In R. E. Ames \& C. Ames (Eds.), Research on motivation in education (Vol. 3,pp. 139-181). New York, NY: Academic Press.

Evans, A. B., Copping, K. E., Rowley, S. J., \& Kurtz-Costes, B. (2011). Academic selfconcept in Black adolescents: Do race and gender stereotypes matter? Self and Identity, 10, 263-277.
Good, C., Aronson, J., \& Inzlicht, M. (2003). Improving adolescents' standardized test performance: An intervention to reduce the effects of stereotype threat. Journal of Applied Developmental Psychology, 24, 645-662.

Graham, S. (2004). "I can, but do I want to?" Achievement values in ethnic minority children and adolescents. In G. Philogene (Ed.), Racial identity in context: The legacy of Kenneth B. Clark (pp. 125-147). Washington, DC: American Psychological Association.

Graham, S., Taylor, A. Z., \& Hudley, C. (1998). Exploring achievement values among ethnic minority early adolescents. Journal of Educational Psychology, 90, 606-620.

Hudley, C., \& Graham, S. (2002). Stereotypes of achievement striving among early adolescents. Social Psychology of Education, 5, 201-224.

Irving, M. A., \& Hudley, C. (2005). Cultural mistrust, academic outcome expectations, and outcome values among African American adolescent men. Urban Education, 40, 476-496.

Jacobs, J. (1991). Influence of gender stereotypes on parent and child mathematics attitudes. Journal of Educational Psychology, 83, 518-527.

Kellow, J. T., \& Jones, B. D. (2008). The effects of stereotypes on the achievement gap: Reexamining the academic performance of African American high school students. The Journal of Black Psychology, 34, 94-120.

Kurtz-Costes, B., Rowley, S. J., Harris-Britt, A., \& Woods, T. A. (2008). Gender stereotypes about mathematics and science and self-perceptions of ability in late childhood and early adolescence. MerrillPalmer Quarterly, 54, 386-409.

Losen, D., \& Orfield, G. (2002). Racial inequality in special education. Cambridge, MA: Harvard Civil Rights Project. Maccoby, E. E. (1998). The two sexes: Growing up apart, coming together. Cambridge, MA: Harvard University Press.

McKown, C., \& Strambler, M. J. (2009). Developmental antecedents and social and academic consequences of stereotype-consciousness in middle childhood. Child Development, 80, 1643 1659.
McKown, C., \& Weinstein, R. S. (2003). The development and consequences of stereotype consciousness in middle childhood. Child Development, 74, 498-515.

Nelson, K. (1996). Event knowledge: Structure and function in development. Hillsdale, NJ: Erlbaum.

Nelson, K., Plesa, D., \& Henseler, S. (1998). Children's theory of mind: An experiential interpretation. Human Development, 41, 7-29.

Nesdale, D., \& Flesser, D. (2001). Social identity and the development of children's group attitudes. Child Development, 72, 506-517.

Okeke, N. A., Howard, L. C., Kurtz-Costes, B., \& Rowley, S. J. (2009). Academic race stereotypes, academic self-concept, and racial centrality in African American youth. The Journal of Black Psychology, 35, 366-387.

Otten, S. (2004). Self-anchoring as predictor of in-group favoritism: Is it applicable to real group contexts? Current Psychology of Cognition, 22, 427-443.

Quintana, S. M. (1998). Racial perspectivetaking ability: Developmental, theoretical, and empirical trends. In S. M. Quintana \& C. McKown (Eds.), Handbook of race, racism, and the developing child (pp. 16-36). Hoboken, NJ: John Wiley.

Rowley, S. J., Kurtz-Costes, B., \& Cooper, S. (2010). Schooling and the development of African American children. In J. Meece \& J. Eccles (Eds.), Handbook of research on schools, schooling, and human development (pp. 275-292). Hillsdale, NJ: Erlbaum.

Rowley, S. J., Kurtz-Costes, B., Mistry, R., \& Feagans, L. (2007). Social status as a predictor of race and gender stereotypes in late childhood and early adolescence. Social Development, 16, 150-168.

Schmader, T., Jones, M., \& Forbes, C. (2008). An integrated process model of stereotype threat effects on performance. Psychological Review, 115, 336-356.

Sekaquaptewa, D., Waldman, A., \& Thompson, M. (2007). Solo status and selfconstrual: Being distinctive influences racial self-construal and performance apprehension in African American women. Cultural Diversity and Ethnic Minority Psychology, 13, 321-327. 
Steele, C. (1997). A threat in the air: How stereotypes shape intellectual identity and performance. The American Psychologist, 52, 613-629.

Steele, C. M., \& Aronson, J. (1995). Stereotype threat and the intellectual test performance of African Americans. Journal of Personality and Social Psychology, 69, 797-811.

Stevens, J. P. (1984). Outliers and influential data points in regression analysis. Psychological Bulletin, 95, 334344.
Tajfel, H. (1970). Experiments in intergroup discrimination. Scientific American, 233, 96-102.

Tiedemann, J. (2001). Parents' gender stereotypes and teachers' beliefs as predictors of children's concept of their mathematical ability in elementary school. Journal of Educational Psychology, 92, 144-151.

Ward, L. M. (2004). Wading through the stereotypes: Positive and negative associations between media use and Black adolescents' conceptions of self. Developmental Psychology, 40, 284-294.
Williams, T. R., Davis, L. E., Cribbs, J. M., Saunders, J., \& Williams, J. H. (2002). Friends, family, and neighborhood: Understanding academic outcomes of African American youth. Urban Education, 37, 408-431.

Wong, C., Eccles, J. S., \& Sameroff, A. (2003). The influence of ethnic discrimination and ethnic identification on African American adolescents' school and socioemotional adjustment. Journal of Personality, 71, 1197-1232. 